\title{
Extreme adaptations for aquatic ectoparasitism in a Jurassic fly larva
}

\author{
Jun Chen ${ }^{1 \dagger}$, Bo Wang ${ }^{2,3 * \dagger}$, Michael S Engel ${ }^{4 \dagger}$, Torsten Wappler ${ }^{2}$, \\ Edmund A Jarzembowski $i^{3,5}$, Haichun Zhang ${ }^{3}$, Xiaoli Wang ${ }^{1}$, \\ Xiaoting Zheng ${ }^{1}$, Jes Rust ${ }^{2}$
}

${ }^{1}$ Institute of Geology and Paleontology, Linyi University, Linyi, China; ${ }^{2}$ Steinmann Institute, University of Bonn, Bonn, Germany; ${ }^{3}$ State Key Laboratory of Palaeobiology and Stratigraphy, Nanjing Institute of Geology and Palaeontology, Chinese Academy of Sciences, Nanjing, China; ${ }^{4}$ Department of Ecology and Evolutionary Biology, University of Kansas, Lawrence, United States; ${ }^{5}$ Department of Earth Sciences, Natural History Museum, London, United Kingdom

*For correspondence: savantwang@gmail.com

tThese authors contributed equally to this work

Competing interests: The authors declare that no competing interests exist.

Funding: See page 7

Received: 19 March 2014

Accepted: 14 May 2014

Published: 24 June 2014

Reviewing editor: Detlef Weigel, Max Planck Institute for Developmental Biology, Germany

(c) Copyright Chen et al. This article is distributed under the terms of the Creative Commons Attribution License, which permits unrestricted use and redistribution provided that the original author and source are credited.
Abstract The reconstruction of ancient insect ectoparasitism is challenging, mostly because of the extreme scarcity of fossils with obvious ectoparasitic features such as sucking-piercing mouthparts and specialized attachment organs. Here we describe a bizarre fly larva (Diptera), Qiyia jurassica gen. et sp. nov., from the Jurassic of China, that represents a stem group of the tabanomorph family Athericidae. Q. jurassica exhibits adaptations to an aquatic habitat. More importantly, it preserves an unusual combination of features including a thoracic sucker with six radial ridges, unique in insects, piercing-sucking mouthparts for fluid feeding, and crocheted ventral prolegs with upward directed bristles for anchoring and movement while submerged. We demonstrate that $Q$. jurassica was an aquatic ectoparasitic insect, probably feeding on the blood of salamanders. The finding reveals an extreme morphological specialization of fly larvae, and broadens our understanding of the diversity of ectoparasitism in Mesozoic insects.

DOI: 10.7554/eLife.02844.001

\section{Introduction}

The early evolution of insect ectoparasites and their associations with hosts are poorly known (Labandeira, 2002; Wappler et al., 2004; Grimaldi and Engel, 2005). Although several Mesozoic insects were regarded as putative ectoparasites, only giant fleas have been widely accepted as definite terrestrial ectoparasitic insects on dinosaurs, pterosaurs, or mammals (Gao et al., 2012, 2013b; Huang et al., 2012, 2013). Here we report on an aquatic ectoparasitic insect based on five well-preserved specimens from the Middle Jurassic Daohugou beds of China. These fossils are extremely rare among the approximately 300,000 fossil insects in the collections of the Nanjing Institute of Geology and Palaeontology and Shandong Tianyu Museum of Nature.

\section{Results}

\section{Systematic paleontology}

Order Diptera Linnaeus, 1758

Family Athericidae Stuckenberg, 1973

Qiyia jurassica gen. et sp. nov.

\section{Etymology}

Qiyia is from the Chinese 'qiyi' meaning bizarre; jurassica is a reference to the Jurassic age of the fossils. 
eLife digest Parasites have been exploiting other organisms for millions of years. However, little is known about ancient parasitic insects, as it is rare to find fossils that are preserved well enough for them to be identified as parasites. This is particularly true for ectoparasitic insects, which live on the skin of their hosts. As a result, the only widely accepted ectoparasitic insect from the Mesozoic era is the giant flea, which infested dinosaurs, pterosaurs or mammals.

Now, Chen, Wang, Engel et al. have discovered a new genus and species of ancient aquatic fly, which may be the earliest currently known aquatic ectoparasitic insect. Named Qiyia jurassica-after the Chinese word for 'bizarre' and the Jurassic period when it lived-its larva has a combination of features that mark it out as a parasitic ancestor of modern water snipe flies. In addition, the well-preserved fossilised larvae used to identify $Q$. jurassica have some more unusual features.

The mouth of $Q$. jurassica had a structure commonly found in ectoparasites, designed to pierce skin and suck blood. The larva also had several features that were particularly well-adapted for gripping the host animal while underwater. The prolegs-stumpy fleshy structures found on the abdomen-were covered in bristles that pointed upwards, anchoring the larva in place. Q. jurassica also had an unusual sucker on its thorax that would have provided a firm grip that held its head still during feeding. Although many modern aquatic ectoparasites-like leeches-have suckers, the Q. jurassica sucker may be unique amongst insect larvae, as it has six large ridges and is covered in spines. Both features may have provided extra grip.

Chen, Wang, Engel et al. suggest that $Q$. jurassica feasted on the blood of salamanders, as many salamander fossils have been found in the same region. The larvae could have attached to unexposed areas of the salamander-behind the gills, for example-where feeding would also have been easier due to the rich supply of blood vessels, and the thinner, more easily pierced skin.

The wide range of features found on $Q$. jurassica suggests that Mesozoic ectoparasitic insects were more diverse than previously thought.

DOI: 10.7554/eLife.02844.002

\section{Type material}

Holotype STMN65-1. Paratypes STMN65-2, NIGP156982, NIGP156983, NIGP156984. All specimens are preserved as carbonaceous impressions on the surface of grey tuffaceous siltstone (Wang et al., 2013).

\section{Locality and age}

From the Middle Jurassic Daohugou beds (approximately 165 million years old) of Ningcheng County, Inner Mongolia, China (Liu et al., 2006).

\section{Diagnosis}

Three thoracic segments fused, with a ventral sucker; two pairs of dorsal spines on abdominal segments 1-7; abdominal segments 1-6 with paired ventral prolegs bearing upward directed bristles and apical crochets; extended seventh proleg; two pairs of anal papillae; sclerotized terminal processes with stiff setae.

\section{Description}

Body elongate, 18-24 mm long (Table 1). Head greatly reduced and partly retractile into thorax (Figure 1A,B); antennae and eyes not visible (Figure 1C); a pair of sclerotized tentorial rods (Figure 2B). Mandibles approximately $0.6 \mathrm{~mm}$ long, heavily sclerotized, sickle-shaped, oriented to move parallel to each other in vertical plane, with external groove on adoral surface extending whole length of mandible (Figure 1E). Thoracic segment swollen, slightly narrower than abdomen (Figure 2A). Sucker retractile, diameter about $2 \mathrm{~mm}$, located ventrally on thoracic segment and consisting of a circular suction disc with central opening about one quarter of disc diameter; peripheral area of disc thin and flexible (Figure 1D). Six robust, sclerotized ridges on sucker, radially arranged, covered by soft skin with small spines (Figure 2D,E); distal part of each ridge thickened, probably with three processes embedded in musculature (Figure 2E). Three pairs of small spines with simple shafts on dorsolateral margins of thorax, two pairs on dorsolateral margins of abdominal segments $1-7$, and one pair 
Table 1. Measurements of specimens of Qiyia jurassica

\begin{tabular}{|c|c|c|c|c|c|}
\hline & $\begin{array}{l}\text { Holotype } \\
\text { STMN65-1 }\end{array}$ & $\begin{array}{l}\text { Paratype } \\
\text { STMN65-2 }\end{array}$ & $\begin{array}{l}\text { Paratype } \\
\text { NIGP156982 }\end{array}$ & $\begin{array}{l}\text { Paratype } \\
\text { NIGP156983 }\end{array}$ & $\begin{array}{l}\text { Paratype } \\
\text { NIGP156984 }\end{array}$ \\
\hline Orientation & lateral & lateral & dorsal & dorsal & lateral \\
\hline Body & 23.8 & 22.1 & 22.9 & $\sim 22$ & 18.1 \\
\hline Head & $\sim 1$ & $\sim 1$ & $\sim 1$ & - & 0.8 \\
\hline Thorax & 2.8 & 2.5 & 2.6 & $\sim 2.5$ & 2.3 \\
\hline Thoracic sucker diameter & 2.0 & 1.9 & - & - & 1.6 \\
\hline Ridge & 0.6 & 0.6 & - & - & 0.5 \\
\hline $\begin{array}{l}\text { Abdominal segments } \\
1-7 \text { (average) }\end{array}$ & $\sim 2.3$ & $\sim 2.2$ & $\sim 2.3$ & $\sim 2.2$ & $\sim 1.9$ \\
\hline Prolegs 1-6 (average) & $\sim 1.5$ & $\sim 1.5$ & $\sim 1.5$ & $\sim 1.5$ & $\sim 1.3$ \\
\hline Seventh proleg & 4.0 & 3.8 & - & - & 3.0 \\
\hline First anal papilla & 6.1 & 6.0 & - & $\sim 6$ & 4.8 \\
\hline Second anal papilla & 3.7 & 3.2 & - & - & - \\
\hline Terminal process & 2.9 & 2.7 & 3.0 & 2.7 & 2.3 \\
\hline
\end{tabular}

All measurements are in $\mathrm{mm}$ and lengths except where otherwise indicated.

: approximately; -: unknown.

DOI: 10.7554/eLife.02844.003

on abdominal segment 8 (Figure 2A). Abdomen with eight distinct segments, covered by many short setae. Abdominal segments 1-6 with a pair of cylindrical, ventral prolegs covered by stiff, upward directed bristles; each proleg nearly half width of body with two rows of six crochet hooks apically (Figure 1F); seventh proleg approximately three times longer than other prolegs with only three or four apical hooks; abdominal segment 8 with two pairs of slender, tapering anal papillae: first pair long, approximately quarter body length; second pair half the length of the first pair (Figure 1A,B); one pair of unsegmented, sclerotized terminal processes fringed with stiff setae, approximately onetenth body length; each process with about 10 spiracles (Figure 1G, Figure 2C).

\section{Discussion}

Three specimens are laterally compressed (STMN65-1, STMN65-2, NIGP156984) and two are dorsoventrally compressed (NIGP156982, NIGP156983), thereby providing side and top views of the detailed morphology of the larva. $Q$. jurassica is attributed to the Tabanomorpha by the reduced and retractable head and sickle-shaped mandibles shifted into a vertical plane (Yeates, 2002; Zloty et al., 2005). It possesses two noticeably plesiomorphic features: mandibles with external grooves (Zloty et al., 2005) and well-developed anal papillae (Wichard et al., 1999), while sharing two potential synapomorphies with extant athericid larvae: paired prolegs with crochet hooks (Yeates, 2002; Kerr, 2010) and long terminal processes fringed with setae (Dobson, 2013). This combination of primitive and derived features demonstrates that $Q$. jurassica is a stem lineage representative of the Athericidae (water snipe flies), a family sister to the more familiar horse flies (Tabanidae). The earliest known Athericidae and Tabanidae (all represented by preserved adults) are from the Early Cretaceous of southern England (Mostovski et al., 2003). Our new fossils are the earliest record of athericid flies and extend the lineage back to the Middle Jurassic, an age which is consistent with predicted divergence times based on molecular studies (estimated at the Early or Middle Jurassic) (Wiegmann et al., 2011).

Q. jurassica displays adaptations to an aquatic habitat, much like extant Athericidae which are today aquatic predators in fast-flowing water (as adults some athericids feed on mammalian or amphibian blood) (Mostovski et al., 2003; Nagatomi and Stuckenberg, 2004). The paired sclerotized terminal processes are morphologically comparable to the modifications of beetle urogomphi in the aquatic larvae of some families such as Dytiscidae (Wichard et al., 1999). About 10 spiracles are present on each process of $Q$. jurassica (Figure 1G, Figure 2C), confirming that they were used for breathing air, functionally similar to the unsclerotized ones of extant athericid larvae (Nagatomi and Stuckenberg, 2004). Q. jurassica also possesses two pairs of anal papillae which are useful for extracting dissolved oxygen from water in aquatic flies and also play an important part in salt absorption to maintain ionic 


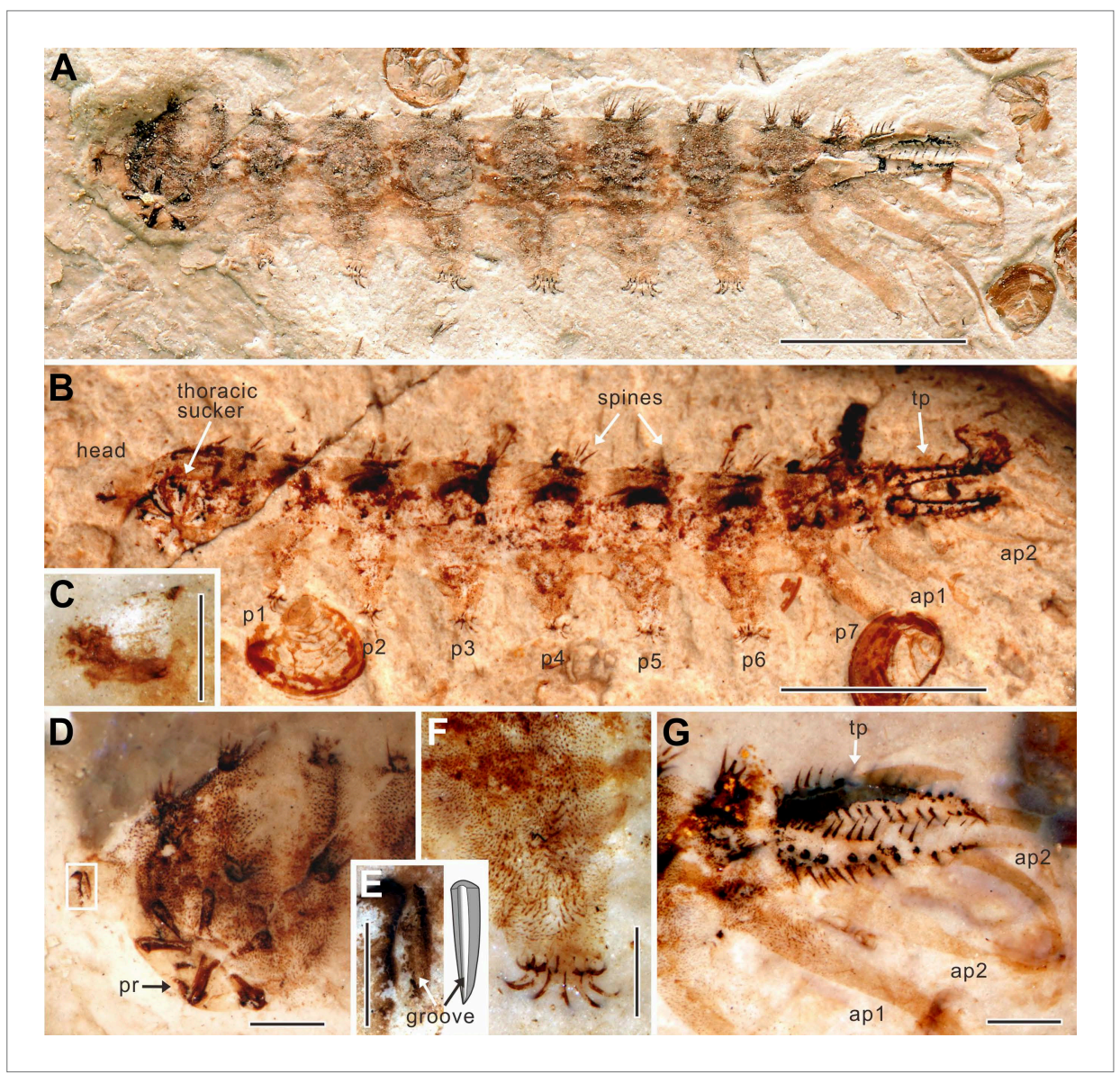

Figure 1. Qiyia jurassica from the Middle Jurassic epoch of Daohugou, China. (A) Holotype STMN65-1. (B) Paratype STMN65-2 under alcohol (horizontal mirror image). (C) Head capsule of paratype STMN65-2. (D) Head and thorax of holotype STMN65-1. (E) Enlargement and reconstruction of the mandible of holotype STMN65-1; note the longitudinal groove. (F) Fifth proleg of holotype STMN65-1; note stiff, upward directed bristles which are distinctly longer than setae on body. (G) Last abdominal segment of holotype STMN65-1. ap, anal papilla; p, proleg; pr, process of ridge; tp, terminal process. (Scale bars: $5 \mathrm{~mm}$ in $\mathbf{A}, \mathbf{B}, 1 \mathrm{~mm}$ in $\mathbf{D}, \mathbf{F}, \mathbf{G}$, and $0.5 \mathrm{~mm}$ in $\mathbf{C}, \mathbf{E}$ ). DOI: 10.7554/eLife.02844.004

concentrations in the body fluids (Wichard et al., 1999). These organs are common in nematoceran larvae and in some lower brachyceran larvae, but are reduced in extant tabanomorphan larvae (Wichard et al., 1999; Dobson, 2013). In the case of the fossil larva, their development implies a plesiomorphic condition.

The most notable structure of these newly discovered fossils is the ridged thoracic sucker which is a unique evolutionary adaptation among holometabolous insects. The round sucker has six radial ridges which are considered to be highly modified thoracic legs (Figure 2D). These six robust, sclerotized ridges could increase both the suction area and surface friction, thus providing more adhesion and increasing lateral stability whilst reducing slippage, like the radial grooves in modern octopus suckers (Kier and Smith, 2002) and supporting ribs in man-made suction cups (Monkman et al., 2007). The dense vestiture of small spines may be used for better anchoring on the corrugated skin of a salamander, like the sucker-ring teeth and knobs on squid suckers (e.g., Miserez et al., 2009). To our knowledge, among insect larvae, only extant blepharicerids (Diptera) have six well-developed suckers, but these are small and without ridges on the abdominal sternites. As blepharicerid larvae graze on periphyton on rocks, they use the suckers to adhere to the substrate in fast-flowing streams (Frutiger, 2002). However, the excellent preservation of our new fossils suggests that $Q$. jurassica did not travel long distances and, unlike crown group Athericidae, most probably lived in still water near to or in the Daohugou palaeolake, a low-energy preservation environment (Wang et al., 2013). The thoracic sucker on $Q$. jurassica is strongly cephalad on the body so, when anchored to the substrate, it probably 


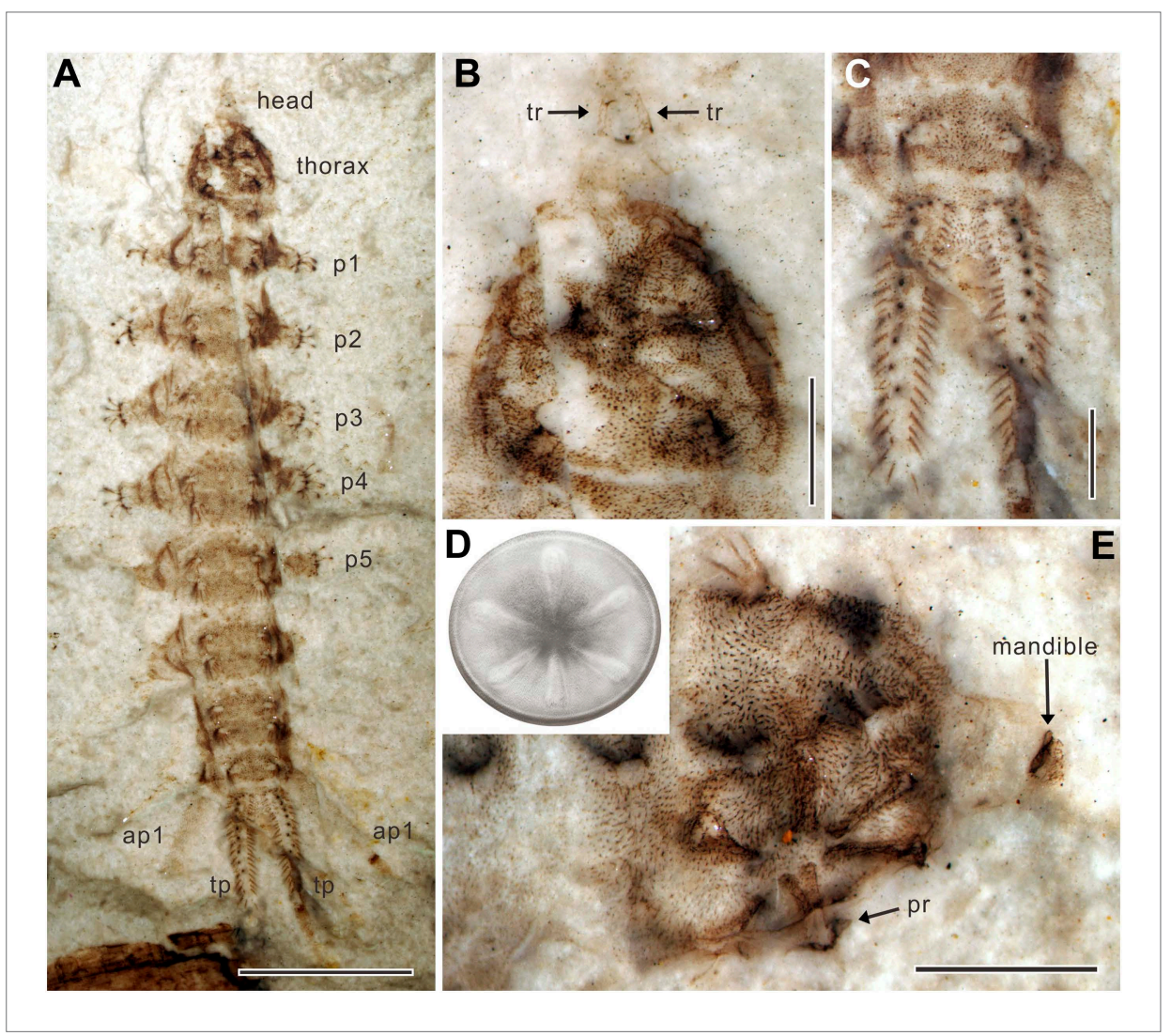

Figure 2. Qiyia jurassica from the Middle Jurassic epoch of Daohugou, China. (A) Paratype NIGP156982 under alcohol. (B) Head and thorax of paratype NIGP156982; note the underlying thoracic sucker. (C) Terminal processes of paratype NIGP156982. (D) Reconstruction of sucker. The sucker consists of a circular suction disc with central opening and thin peripheral area. Six robust, radially arranged ridges are covered by soft skin with small spines. (E) Head and thorax of paratype NIGP156984; note the deformed mandible. ap, anal papilla; p, proleg; pr, process of ridge; tp, terminal process; tr, tentorial rod. (Scale bars: $5 \mathrm{~mm}$ in $\mathbf{A}, 1 \mathrm{~mm}$ in B, C, E). DOI: 10.7554/eLife.02844.005

restricted the movement of the small, short head (Figure 1D, Figure 2E), a condition that is clearly suitable for piercing and sucking (Figure 3). Suckers are widespread in aquatic ectoparasites such as leeches, fish lice, and lampreys (Kearn, 2004) which require more suction power to avoid becoming dislodged; other aquatic ectoparasites without attachment organs embed themselves in skin or muscle, such as cyclopoid copepods (anchor worms) (Kearn, 2004). In addition to the sucker, the stiff, upward directed bristles and apical hooks on the prolegs (Figure 1F) are also specialized attachment structures. These morphological adaptations provide compelling evidence that $Q$. jurassica adhered to a host as an ectoparasite, providing further specialization for a dense, watery habitat.

Bloodsucking is considered to have evolved independently at least 12 times in true flies (Lukashevich and Mostovski, 2003; Wiegmann et al., 2011). It started with free-living scavengers or predators which subsequently became opportunistic feeders on vertebrates, such as the notorious Congo floor maggot (Auchmeromyia) that consumes the blood of sleeping humans (Lehane, 2005). Bloodsuckers are present as adults in three families of extant Tabanomorpha (Nagatomi and Stuckenberg, 2004). Although hitherto known larval Tabanomorpha are mainly predators, some larvae suck the body fluids of vertebrates such as anurans (Jackman et al., 1983). Predatory fly larvae commonly have morphological and physiological adaptations (such as efficient protein-digesting enzymes and salivary glands), facilitating the switch to bloodsucking (Balashov, 1984; Lehane, 2005). Q. jurassica has a pair of sickle-shaped mandibles with external grooves (Figure 1E), which is a groundplan character of Tabanomorpha (Wichard et al., 1999; Yeates, 2002), forming a channel when the left and right mandibles are occluded (Zloty et al., 2005) and used for sucking blood or other body fluids (Marshall, 1981). 


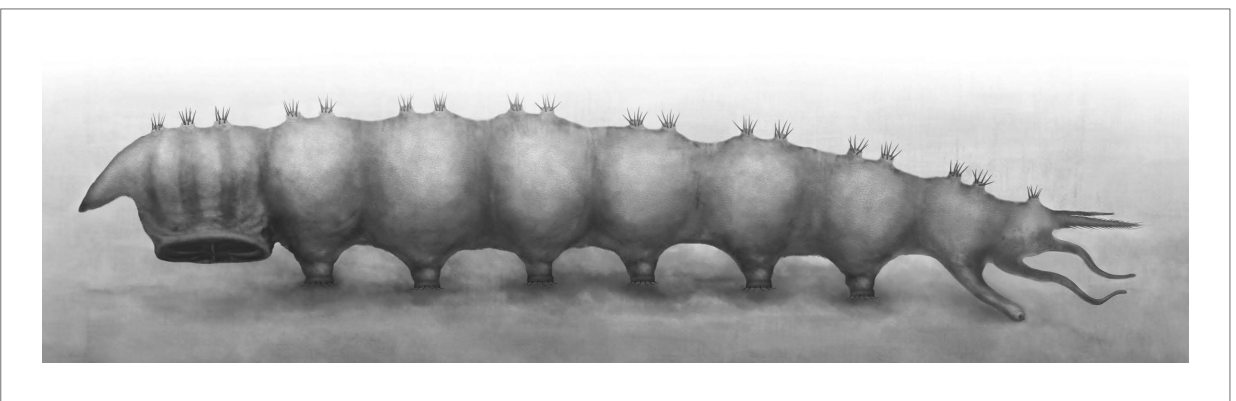

Figure 3. Reconstruction of Qiyia jurassica in lateral view. DOI: 10.7554/eLife.02844.006

The following figure supplements are available for figure 3:

Figure supplement 1. Ecological restoration of Qiyia jurassica from the Middle Jurassic epoch of Daohugou, China.

DOI: 10.7554/eLife.02844.007

In the Daohugou deposits fish are completely absent but salamanders are extremely abundant (several thousand specimens recovered to date) (Liu et al., 2006). The most common salamanders at Daohugou, Chunerpeton tianyiensis and Jeholotriton paradoxus, have body lengths of $500 \mathrm{~mm}$ and $150 \mathrm{~mm}$, respectively (Wang and Rose, 2005). Both species display neotenic features and are fully aquatic in all stages of their life cycle (Gao et al., 2013a). Salamander skin is glabrous and thin, and could easily have been penetrated by the mandibles of a larva such as $Q$. jurassica. The Daohugou salamanders match $Q$. jurassica well in size as well as co-occurrence, suggesting a possible parasite-host relationship. Some extant fly larvae parasitize anurans by burrowing into the skin, including Calliphoridae, Sarcophagidae, and Chloropidae (Hoskin and McCallum, 2007), and sometimes cause substantial mortality in their hosts (Bolek and Coggins, 2002). Q. jurassica, however, could simply have been anchored to the salamander skin using its sucker and prolegs (Figure 3-figure supplement 1), in a similar manner to leeches and fish lice (Kearn, 2004).

Despite a great taxonomic diversity of extant ectoparasitic insects (Marshall, 1981), previous definite Mesozoic records were confined to the terrestrial giant fleas from the Middle Jurassic and Early Cretaceous epochs (Gao et al., 2012, 2013b; Huang et al., 2012). Q. jurassica, which is arguably the earliest known aquatic ectoparasitic insect, reveals an unexpected morphological specialization of fly larvae and highlights the diversity of ectoparasitism in the Mesozoic.

\section{Materials and methods}

The specimens are housed in the Shandong Tianyu Museum of Nature (STMN), Pingyi, China, and Nanjing Institute of Geology and Palaeontology (NIGP), Chinese Academy of Sciences. Photographs were taken using a Zeiss Discovery V8 microscope system with specimens moistened in $95 \%$ alcohol or dry. The figures were prepared with CorelDraw X4 and Adobe Photoshop CS3.

\section{Nomenclatural acts}

The electronic edition of this article conforms to the requirements of the amended International Code of Zoological Nomenclature, and hence the new names contained herein are available under that Code from the electronic edition of this article. This published work and the nomenclatural acts it contains have been registered in ZooBank, the online registration system for the ICZN. The ZooBank LSIDs (Life Science Identifiers) can be resolved and the associated information viewed through any standard web browser by appending the LSID to the prefix 'http://zoobank.org/'. The LSID for this publication is: urn:Isid:zoobank.org:pub: 99FE7164-CF29-4EAE-B7B2-40C727CAC4FA. The electronic edition of this work was published in a journal with an ISSN, and has been archived and is available from the following digital repositories: PubMed Central, CLOCKSS, Linyi University, Steinmann Institute at University of Bonn, and Nanjing Institute of Geology and Palaeontology (CAS). Printed copies are deposited in six major publicly accessible libraries including Linyi University, Nanjing Institute of Geology and Palaeontology (CAS), Steinmann Institute at University of Bonn, University of Kansas, Natural History Museum (London), and Muséum National d'Histoire Naturelle in Paris. 


\section{Acknowledgements}

We are grateful to Xing Xu, Yuan Wang, Alexandr Rasnitsyn, and Junfeng Zhang for discussions on these specimens, Daran Zheng for his help in the preparation of specimens, Dinghua Yang for reconstructions, and André Nel and Enrique Peñalver for their constructive reviews.

Additional information

This research was supported by the National Basic Research Program of China (2012CB821900), National Natural Science Foundation of China (41272013, 41372014, J1210006), Natural Scientific Foundation of Shandong Province (ZR2013DQ017), CAS 2011T2Z04, and partially from US National Science Foundation grant DEB-0542909. BW was also supported by a Research Fellowship from the Alexander von Humboldt Foundation.

\section{Additional information}

\begin{tabular}{|c|c|c|}
\hline Funder & $\begin{array}{l}\text { Grant reference } \\
\text { number }\end{array}$ & Author \\
\hline $\begin{array}{l}\text { Alexander von Humboldt } \\
\text { Foundation }\end{array}$ & CHN 1149090 STP & Bo Wang \\
\hline $\begin{array}{l}\text { National Basic Research } \\
\text { Program of China }\end{array}$ & 2012CB821900 & $\begin{array}{l}\text { Jun Chen, Bo Wang, } \\
\text { Edmund A Jarzembowski, } \\
\text { Haichun Zhang, Xiaoli Wang, } \\
\text { Xiaoting Zheng }\end{array}$ \\
\hline $\begin{array}{l}\text { National Natural Science } \\
\text { Foundation of China (NSFC) }\end{array}$ & $\begin{array}{l}\text { 41272013, 41372014, } \\
\text { J1210006 }\end{array}$ & $\begin{array}{l}\text { Jun Chen, Bo Wang, } \\
\text { Edmund A Jarzembowski, } \\
\text { Haichun Zhang, Xiaoli Wang, } \\
\text { Xiaoting Zheng }\end{array}$ \\
\hline $\begin{array}{l}\text { Natural Scientific Foundation } \\
\text { of Shandong Province }\end{array}$ & ZR2013DQ017 & Jun Chen \\
\hline $\begin{array}{l}\text { National Science Foundation } \\
\text { (NSF) }\end{array}$ & DEB-0542909 & Michael S Engel \\
\hline $\begin{array}{l}\text { Chinese Academy of Sciences } \\
\text { (CAS) }\end{array}$ & CAS 2011T2Z04 & Edmund A Jarzembowski \\
\hline
\end{tabular}

The funders had no role in study design, data collection and interpretation, or the decision to submit the work for publication.

Author contributions

JC, MSE, Acquisition of data, Analysis and interpretation of data, Drafting or revising the article, Contributed unpublished essential data or reagents; BW, Conception and design, Acquisition of data, Analysis and interpretation of data, Drafting or revising the article, Contributed unpublished essential data or reagents; TW, EAJ, Analysis and interpretation of data, Drafting or revising the article; $\mathrm{HZ}$, $\mathrm{XW}, \mathrm{XZ}$, Acquisition of data, Analysis and interpretation of data; JR, Acquisition of data, Analysis and interpretation of data, Drafting or revising the article

\section{References}

Balashov Y. 1984. Interaction between blood-sucking arthropods and their hosts, and its influence on vector potential. Annual Review of Entomology 29:137-156. doi: 10.1146/annurev.en.29.010184.001033.

Bolek MG, Coggins JR. 2002. Observations on myiasis by the calliphorid, Bufolucilia silvarum, in the eastern American toad (Bufo americanus americanus) from southeastern Wisconsin. Journal of Wildlife Diseases 38:598-603. doi: 10.7589/0090-3558-38.3.598.

Dobson M. 2013. Family-level keys to freshwater fly (Diptera) larvae: a brief review and a key to European families avoiding use of mouthpart characters. Freshwater Reviews 6:1-32. doi: 10.1608/FRJ-6.1.450.

Frutiger A. 2002. The function of the suckers of larval net-winged midges (Diptera: Blephariceridae). Freshwater Biology 47:293-302. doi: 10.1046/j.1365-2427.2002.00814.x.

Gao KQ, Chen JY, Jia J. 2013a. Taxonomic diversity, stratigraphic range, and exceptional preservation of Juro-Cretaceous salamanders from northern China. Canadian Journal of Earth Sciences 50:255-267. doi: 10.1139/e2012-039. 
Gao TP, Shih C, Rasnitsyn AP, Xu X, Wang S, Ren D. 2013b. New transitional fleas from China highlighting diversity of Early Cretaceous ectoparasitic insects. Current Biology 23:1261-1266. doi: 10.1016/j. cub.2013.05.040.

Gao TP, Shih C, Xu X, Wang S, Ren D. 2012. Mid-Mesozoic flea-like ectoparasites of feathered or haired vertebrates. Current Biology 22:732-735. doi: 10.1016/j.cub.2012.03.012.

Grimaldi DA, Engel MS. 2005. Evolution of the insects. Cambridge: Cambridge University Press.

Hoskin CJ, McCallum H. 2007. Phylogeography of the parasitic fly Batrachomyia in the wet tropics of north-east Australia, and susceptibility of host frog lineages in a mosaic contact zone. Biological Journal of the Linnean Society 92:593-603. doi: 10.1111/j.1095-8312.2007.00862.x.

Huang D, Engel MS, Cai C, Wu H, Nel A. 2012. Diverse transitional giant fleas from the Mesozoic era of China. Nature 483:201-204. doi: 10.1038/nature10839.

Huang D, Nel A, Cai C, Lin Q, Engel MS. 2013. Amphibious flies and paedomorphism in the Jurassic period. Nature 495:94-97. doi: 10.1038/nature11898.

Jackman R, Nowicki S, Aneshansley DJ, Eisner T. 1983. Predatory capture of toads by fly larvae. Science 222:515-516. doi: 10.1126/science.222.4623.515.

Kearn GC. 2004. Leeches, lice and lampreys. A natural history of skin and gill parasites of fishes. Dordrecht: Springer.

Kerr PH. 2010. Phylogeny and classification of Rhagionidae, with implications for Tabanomorpha (Diptera: Brachycera). Zootaxa 2592:1-133.

Kier WM, Smith AM. 2002. The structure and adhesive mechanism of octopus suckers. Integrative and Comparative Biology 42:1146-1153. doi: 10.1093/icb/42.6.1146.

Labandeira CC. 2002. Paleobiology of predators, parasitoids, and parasites: death and accommodation in the fossil record of continental invertebrates. In: Kowalevski M, Kelley PH, editors. The fossil record of predation. Paleontological Society, Yale Printing Service. p. 211-249.

Lehane MJ. 2005. The biology of blood-sucking in insects. New York: Cambridge University Press.

Liu YQ, Liu YX, Ji SA, Yang ZQ. 2006. U-Pb zircon age for the Daohugou Biota at Ningcheng of Inner Mongolia and comments on related issues. Chinese Science Bulletin 51:2634-2644. doi: 10.1007/s11434-006-2165-2.

Lukashevich ED, Mostovski MB. 2003. Hematophagous insects in the fossil record. Journal of Paleontology 37:153-161.

Marshall AG. 1981. The ecology of ectoparasitic insects. London: Academic Press.

Miserez A, Weaver JC, Pedersen PB, Schneeberk T, Hanlon RT, Kisailus D, Birkedal H. 2009. Microstructural and biochemical characterization of the nanoporous sucker rings from Dosidicus gigas. Advanced Materials 21:401-406. doi: 10.1002/adma.200801197.

Monkman GJ, Hesse S, Steinmann R, Schunk H. 2007. Robot grippers. Weinheim: Wiley-VCH.

Mostovski MB, Jarzembowski EA, Coram RA. 2003. Horseflies and athericids (Diptera: Tabanidae, Athericidae) from the Lower Cretaceous of England and Transbaikalia. Journal of Paleontology 37:162-169.

Nagatomi A, Stuckenberg BR. 2004. Insecta: Diptera, Athericidae. In: Yule CM, Sen YH, editors. Freshwater Invertebrates of the Malaysian Region. Kuala Lumpur, Malaysia: Academy of Sciences Malaysia. p. 791-797.

Wang B, Zhang HC, Jarzembowski EA, Fang Y, Zheng DR. 2013. Taphonomic variability of fossil insects: a biostratinomic study of Palaeontinidae and Tettigarctidae (Insecta: Hemiptera) from the Jurassic Daohugou Lagerstätte. Palaios 28:233-242. doi: 10.2110/palo.2012.p12-045r.

Wang Y, Rose C. 2005. Jeholotriton paradoxus (Amphibia: Caudata) from the Lower Cretaceous of south eastern Inner Mongolia, China. The Journal of Vertebrate Paleontology 25:523-532. doi: 10.1671/0272-4634 (2005)025[0523:JPACFT]2.0.CO;2.

Wappler T, Smith VS, Dalgleish RC. 2004. Scratching an ancient itch: an Eocene bird louse fossil. Proceedings Biological Sciences/The Royal Society 271:s255-s258. doi: 10.1098/rsbl.2003.0158.

Wichard W, Arens W, Eisenbeis G. 1999. Atlas zur Biologie der Wasserinsekten. Berlin: Spektrum Akademischer Verlag.

Wiegmann BM, Trautwein MD, Winkler IS, Barr NB, Kin JW, Lambkin C, Bertone MA, Cassel BK, Bayless KM, Heimberg AM, Wheeler BM, Peterson KJ, Pape T, Sinclair BJ, Skevington JH, Blagoderov V, Caravas J, Kutty SN, Schmidt-Ott U, Kampmeier GE, Thompson FC, Grimaldi DA, Beckenbach AT, Courtney GW, Friedrich M, Meier R, Yeates DK. 2011. Episodic radiations in the fly tree of life. Proceedings of the National Academy of Sciences of the United States of America 108:5690-5695. doi: 10.1073/pnas.1012675108.

Yeates DK. 2002. Relationships of extant lower Brachycera (Diptera): a quantitative synthesis of morphological characters. Zoologica Scripta 31:105-121. doi: 10.1046/j.0300-3256.2001.00077.x.

Zloty J, Sinclair BJ, Pritchard G. 2005. Discovered in our backyard: a new genus and species of a new family from the Rocky Mountains of North America (Diptera, Tabanomorpha). Systematic Entomology 30:248-266. doi: 10.1111/j.1365-3113.2005.00270.x. 